\title{
Research on Open Teaching Mode Based on CDIO Concept
}

\author{
Yan $\mathrm{Bao}^{\mathrm{a}^{*}}$, Hongtao $\mathrm{Yu}^{\mathrm{b}}$, Sen $\mathrm{Wang}^{\mathrm{c}}$ and Ziwei Wang ${ }^{\mathrm{d}}$ \\ College of Automation, Shenyang Institute of Engineering, Shenyang Liaoning110136, China \\ adianzixinxi2004@163.com, bneu970773@sohu.com, 'wangs@sie.edu.cn, 'wangzw@sie.edu.cn
}

Keywords: CDIO; Practical teaching method; Teaching management; Collaborative innovation; Teaching mode

\begin{abstract}
CDIO concept is introduced into practical teaching. The practical teaching methods and practical management are discussed based on the project. The purpose of the study is to establish a perfect practical teaching management method, cultivate college students' innovation ability and practical ability of engineering practice.
\end{abstract}

\section{Introduction}

Nowadays, the shortage of engineering talents and the quality of engineering education have become common topics in the world. Engineering education is an important channel for the national economic construction to provide engineering and technical personnel. In order to cultivate a large number of high-quality engineering and technical personnel, improve the national engineering education quality, enhance the international, competitiveness of countries around the world have carried out the reform of engineering education, to meet the national demand for talent, the CDIO Theory is created in this background. On the basis of the CDIO Theory, the study of Practical Teaching mode will be an effective way to make college engineering education more successful. This is also the embodiment of collaborative innovation [1].

CDIO education, that is, Conceive, Design, Implement and Operate engineering education. In this study, "CDIO focus on the Practical Teaching model" means that based on setting up the CDIO Theory model. This paper analyzes the influence of CDIO Practical Teaching courses on the teaching activities of teachers' practice and teaching at home and abroad to discuss deeply the CDIO Theory of " $1+1$ " Practical Teaching mode. This theory is applicable to all types of institutions of higher learning undergraduate, college level professional Practical Teaching.

Use italic for emphasizing a word or phrase. Do not use boldface typing or capital letters except for section headings (cf. remarks on section headings, below).

\section{Current Research Status Level}

In recent years, more and more universities and educators have adopted and recognized the CDIO engineering education model.The concepts which are "project based education" and "learning by doing" provide a good solution and scheme for Chinese higher engineering education connect into international standards.

In the practical application of CDIO, engineering education and research in China is still too late. At the beginning, only a small number of colleges and universities become CDIO pilot colleges and Universities, such as, in other provinces, Shantou University, major in machinery, major in civil engineering, Zhejiang University of Technology, major in machinery, etc. It is worth mentioning that in the pilot colleges and universities, only one college in the province, Dalian Neusoft Information Institute, is listed as CDIO pilot colleges. To sum up, at home and abroad, the relevant theory of CDIO has been studied and practice. But there is not much research on the open teaching mode of integrating the CDIO idea into Practical Teaching, which is also the content of our urgent need for specific research. 


\section{Significance and Value of Research}

Some scholars have pointed out that although the development of CDIO engineering education in China is fast and large, there is a serious shortage of engineering and innovative practice. According to the world leaders of the financial sector summit released 2011-2012 global competitiveness report shows. China's international competitiveness ranked 26 in the world. the lack of high-quality engineering and technical personnel is the key to China's lack of core competitiveness.2013, the Ministry of education had done a report called "the implementation of the connotation of the development requirements, and further promote the reform of engineering education". The report from three aspects of a detailed description. They are the connotation of the development of higher education requirements, further promote the reform of engineering education, promotion of CDIO engineering education model. This paper focuses on the basic situation of CDIO engineering education, and points out that CDIO engineering education is developing very quickly. Practical Teaching in Colleges and universities is an important part of personnel training. It is necessary to explore effective and Practical Teaching methods to improve students' ability of the CDIO project, so that students have the ability to apply theoretical knowledge to solve practical problems. Committed to train the engineering technology talents to adapt to the development of modern society, the CDIO Theory is introduced into engineering Practical Teaching. The project as the main line. In the construction of based CDIO Theory, discuss the emphasis on Practical Teaching methods, Practical Teaching management, establish perfect Practical Teaching management method becomes particularly important. Through the discussion of CDIO open teaching mode and implementation scheme to provides reference for the implementation of CDIO Practical Teaching. It is of profound significance and profound research value to enable the students to have a solid engineering and technical ability, and to be able to be employed in the field of engineering [2-4].

\section{On the Research Framework of Practical Teaching Mode}

Development Situation of CDIO Practical Teaching. In recent years, more and more universities and educators have adopted and recognized the CDIO engineering education model. The concepts which are "project based education" and "learning by doing" provide a good solution and scheme for Chinese higher engineering education connect into international standards.

In the aspect of theoretical research of CDIO in recent years, search related articles, in China How Net with CDIO keyword articles, although there are a thousand articles, but most of the concepts and influence about the concept of CDIO. To "CDIO Practical Teaching" as the key words, a total of 349 related documents. Further analysis, the contents of these documents can be summarized into several categories: The reform of experimental course under the CDIO educational theory; How to carry out CDIO Practical Teaching in some pilot universities; How to carry out laboratory management based CDIO Theory [5].

Engineering practice teaching process of open should focus on the cultivation of innovative thinking and creative ability, through the reform of teaching contents and teaching methods, using modern teaching methods, strengthening the practice teaching interest, make students realize strong practical ability is very important for future development. At the same time, we can deepen the understanding of theoretical knowledge in practice, improve the practical ability, and promote the students to form the consciousness of active thinking and self innovation. Teaching process emphasizes the construction of practice teaching content. It relates to the perfection of teaching syllabus, the supplement of teaching content, the making of courseware, and the process of processing the workpiece from the design to the operation. In addition, the practice of open engineering practice should also emphasize the practical effect of improving the employability of students. The employment ability of the strong and weak, directly reflected in the four years of undergraduate education in the course of the students in the process of recognition of the extent of the community, but also reflects the high quality and low level of their own comprehensive quality. The continuous improvement of students' employment ability should be the most direct teaching achievement in the implementation of the new engineering practice teaching process. In order to achieve the purpose of teaching, should be in engineering practice and four years of 
undergraduate teaching, around the "ladder of experiential education engineering quality education innovation education" the rise of the teaching process, let students to experience in the engineering practice of the atmosphere, to experience in the simulated production enterprise environment, improve their own quality of experience in engineering in the process, exercise their own ability to innovate. Only in this way, students can participate in the engineering practice, and constantly improve the understanding of the problem, think about the problem, the ability to solve practical problems in the project, enhance the confidence to participate in social competition. Thus, the open engineering practice teaching process should reflect the characteristics of the three aspects. First of all, the teaching plan of engineering practice courses should be continuous, which should be carried out in the four year training process of undergraduate students. Students have the opportunity to participate in the engineering practice in grade one to grade four. The engineering practice can be divided into several steps, such as cognitive practice, manufacturing process practice, innovation, skill training and so on. Secondly, the content of engineering practice teaching should keep pace with the situation, and it is an important prerequisite for the realization of the goal of open talents training in the reform and innovation of the prerequisite engineering practice teaching system which is necessary to retain the traditional teaching content. It involves the adjustment of teaching plan, teaching content, laboratory construction, and so on, to establish a multi-level, continuous engineering and technical personnel training system [6-9].

The reasonable setting of teaching content, the formation of a continuous, through the student learning career of the practice teaching system for students to exercise their own engineering quality is very important. Must be careful teaching and the students throughout the learning process, which can be divided into basic, and professional knowledge, the three part, combined with the cultivation of ability and quality, determine the project in the organization in the teaching, the organic integration of engineering teaching activities.

\section{Ideas of the Framework of the Practical Teaching based on CDIO Theory}

"1 + 1": a plan, "1+1": a plan, the other one is project. This establishes the two pivot of CDIO Practical Teaching. Support all kinds of college students' practice activity development plan; Encourage students, college students' practice of science and technology support project.

Vigorously support the development of various types of College Students' practical activitie.

Encourage students to participate actively and vigorously support the promotion of scientific and technological practice projects.

CDIO attaches importance to the establishment of Practical Teaching model.

Attaching importance to the construction of teaching content in Practical Teaching (Construction of practical curriculum, Make practical curriculum networking, Developing teaching resources).

To guide students to study independently in learning interest.

Open practical project construction.

Implementation scheme of CDIO Practical Teaching management.

Integrated Practical Teaching management.

Evaluation of CDIO ability of students and teachers to enhance this ability.

CDIO attaches great importance to the practice teaching model is established in this paper. Pay more attention to the construction of the teaching content of practice teaching curriculum construction, practice, practice network, develop teaching resources CDIO attaches great importance to the practice teaching model is established in this paper; In the interest in learning to efficiently guide students independent learning; Open practice projects; CDIO attaches great importance to the practice teaching management of the implementation of the scheme; The integration of practice teaching management; Students and teachers CDIO capability assessment and ascend [10].

Practice teaching management system and management mechanism of synergy to cooperate. The practice teaching management relationship management system and management mechanism; Can begin to construct the practice teaching of collaborative innovation center, determine the practice teaching of mutual learning, cooperation, integration and synergy stage comprehensive cooperative innovation mechanism, promote the development of practice teaching in colleges and universities. 


\section{Coordination of Management System and Management Mechanism of Practical Teaching in Colleges and Universities}

The relationship between management system of Practical Teaching and management mechanis.

The necessity of coordination and cooperation between management system of Practical Teaching and management mechanism.

To set up the center of Practical Teaching innovation, it is necessary to set up the mechanism of cooperative innovation, such as mutual learning, cooperation, integration and cooperation, to promote the development of Practical Teaching in Colleges and universities.

\section{Conclusion}

CDIO Theory is introduced into Practical Teaching of engineering major. The project as the main line. Based on CDIO Theory discussing the Practical Teaching methods and Practical Teaching management, to establish a perfect Practical Teaching management method is a very meaningful research work. In the future, we will have a further discussion and Research on this subject. Through the discussion of CDIO open teaching mode and implementation scheme to provides reference for the implementation of CDIO Practical Teaching. It is of profound significance and profound research value to enable the students to have a solid engineering and technical ability, and to be able to be employed in the field of engineering.

\section{Acknowledgements}

This work was supported in part by Liaoning Province Education Science "13th Five-Year Plan" project under Grant No. JG16DB321, JG16DB523 and "12th Five-Year Plan"project under Grant No. JG15DB290.

\section{References}

[1] W Wang and DJ Wang: Journal of Anhui Normal University, AM Shen Journal of Anhui Normal University. (2010)

[2] Jianjun LI and J Song: Construction and Exploration of Chemical Engineering Practice Systeaching Based on the Concept of CDIO

[3] Yan-Ze LI,XD Zhang,ZY Yang Journal of Guangdong Polytechnic Normal University. (2013)

[4] RQ Chen: Advanced Materials Research. (2014)

[5] XQ Wu,TL Liu and ZA Yi: International Conference on Computer Science \& Education (2012)

[6] X Wang,J Fan and G Sun: International Conference on Computer Science \& Education. (2012)

[7] Y Gao, J Liu and C Xie: International Conference on Information Technology in Medicine \& Education. (2015)

[8] L Chen : Research of Engineering Capacity Cultivation Based on CDIO Scheme for the Major of Network Engineering.(2016)

[9] G Chen: Practice and Exploration of Teaching Reform of Object-Oriented Programming Course Based on CDIO Concept.(2016)

[10] Information on http://www.weld.labs.gov.cn 